\title{
La retroacció correctiva oral amb estudiants adults poc escolaritzats
}

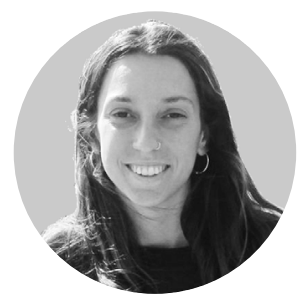

MARIA TERESA SANS BERTRAN

UNIVERSITAT AUTÒNOMA DE BARCELONA

teresasansbertran@msn.com

els últims anys, la retroacció correctiva ha despertat molt interès i s'han dut a terme un nombre considerable de recerques en aquest àmbit, especialment en la didàctica de l'anglès com a llengua segona o estrangera. Malgrat això, els estudis sobre l'ensenyament del català com a llengua addicional són encara incipients. Aquest article se centra en la retroacció correctiva oral que la docent proporciona a l'alumnat quan produeix un enunciat que conté un error en un context d'ensenyament del català com a llengua addicional amb alumnes poc escolaritzats d'un centre educatiu en seu penitenciària. Per dur a terme l'estudi, es van enregistrar 5 sessions d'aula, que es van transcriure i codificar per a l'anàlisi. Els resultats mostren que hi ha un alt nombre d'errors de pronunciació i de lèxic, a banda d'un ús freqüent del castellà (llengua compartida amb la docent) quan s'espera que l'alumnat utilitzi el català. Pel que fa a les estratègies de retroacció correctiva oral, les més freqüents són les reformulacions i les traduccions. Les incitacions són menys freqüents, però destaquen les peticions d'aclariment i les elicitacions. En la majoria dels casos, l'alumnat percep la retroacció correctiva oral proporcionada per la docent. Amb les reformulacions i les traduccions, el nombre de respostes dels alumnes és molt alt, però només un terç de les ocasions condueix a la reparació. Les incitacions són les estratègies que provoquen una correcció de l'error per part dels alumnes amb més freqüència.

\section{PARAULES CLAU:}

retroacció correctiva oral; resposta dels alumnes a la retroacció; ensenyament del català com a llengua addicional; interacció a l'aula; alumnes adults poc escolaritzats

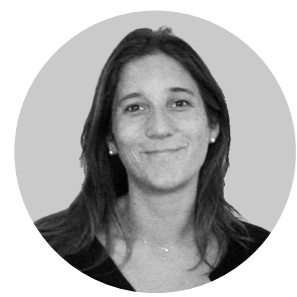

MARILISA BIRELLO

UNIVERSITAT AUTÒNOMA DE BARCELONA

marilisa.birello@uab.cat

a

n recent years, corrective feedback has aroused much interest and a considerable number of studies have been carried out in this field, especially in English as a second or foreign language, but in Catalan as an additional language it is still in its early stages. This article focuses on the oral corrective feedback that the teacher provides to the students when they produce an utterance that contains an error in a context of Catalan as an additional language with low-educated adult students of an educational center located in a penitentiary context. Data were collected during 5 lessons that were recorded, transcribed and coded for the analysis. The results of the study show that there is a high number of mistakes of pronunciation and lexicon, apart from frequent use of Spanish (language shared with the teacher) when the students are expected to use Catalan. Furthermore, related with oral corrective feedback, the findings show that the most common strategies are recasts and translations. Prompts are less common, but clarification requests and elicitation stand out. Finally, in most cases, students notice the oral corrective feedback provided. With recasts and translations the number of uptake is very high, but only a third of the cases conduct to repair. Prompts lead students to a correction of the error by the students more frequently.

\section{KEYWORDS:}

oral corrective feedback; uptake; Catalan as an additional language; classroom interaction; low-educated adult students 


\section{Introducció}

L a funció de la retroacció correctiva oral (oral corrective feedback) que l'estudiant rep a partir d'un enunciat erroni durant una interacció ha estat el focus d'interès de molts estudis, que han mostrat la importància de la retroacció correctiva oral (RCO) en l'aprenentatge d'una llengua addicional (Lyster i Ranta, 1997; Panova i Lyster, 2002; Ranta i Lyster, 2007; Ellis, 2009; Nassaji, 2009; Fu i Nassaji, 2016, entre altres). Tanmateix, la majoria d'aquests estudis es van dur a terme amb alumnes amb alts graus d'escolarització $i$, fins ara, han estat pocs els estudis que han investigat la RCO amb alumnes poc escolaritzats (Tarone, 2021). La majoria de les recerques es van desenvolupar en l'àmbit de l'ensenyament de l'anglès com a llengua addicional, o bé en l'ensenyament de l'espanyol com a llengua addicional (Ferreira, 2006; Veliz Campos, 2008; Alonso Aparicio, 2010; Sánchez Calderón, 2014; Bailini, 2020; Muñoz Moreno i Mavrou, 2020, entre altres). És per això que cal comprovar la seva eficàcia en contextos i combinacions lingüístiques diferents (Fu i Nassaji, 2016), així com amb alumnes que tenen una alfabetització emergent (Tarone, 2010; 2021). L'objectiu d'aquest article és estudiar la RCO i la resposta dels estudiants (uptake) a la retroacció en l'àmbit de l'ensenyament del català com a llengua addicional $\mathrm{i}$ amb un perfil d'alumnes poc escolaritzats.

\section{Retroacció correctiva oral i resposta dels estudiants}

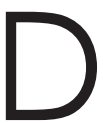

urant les interaccions que tenen lloc a l'aula, és freqüent que es produeixin errors en els enunciats dels alumnes i que els docents decideixin quins errors cal corregir i quina RCO cal oferir. Els estudis inicials van mostrar que era millor si, d'una banda, el docent centrava més l'atenció en els errors més freqüents i que dificultaven la comprensió del missatge (Hendrickson, 1978) i, de l'altra, implicava altres alumnes en la correcció de manera que es creés un ambient més distès i de cooperació a l'aula (James, 1998). D'aquesta manera es podia limitar la sensació d'infantilisme o d'inhibició adulta generada pel fet de no haver quedat bé o d'haver estat corregits públicament (Fernández López, 1995). Pel que fa al tipus d'errors comesos més freqüentment, Ferreira (2006) va mostrar que, en els grups d'estudiants principiants, els errors més comuns eren de gramàtica i pronunciació mentre que en els nivells superiors anaven lligats a errors de gramàtica i lèxic. Jimenez (2006), en el seu estudi amb alumnes italians universitaris que estaven aprenent anglès, va destacar un error molt freqüent que consistia en fer un ús no sol·licitat de la L1 (italià) quan l'alumne podria haver utilitzat l'anglès perquè els seus coneixements li ho permetien. Aquest tipus d'error va rebre RCO en més del 90\% dels casos quan s'havia fet amb el grup gran. En canvi, això no passava quan la correcció era entre companys i, en tot cas, quan la correcció era explícita.

En aquest estudi entenem la RCO com qualsevol reacció del docent que transformi clarament, desaprovi o exigeixi una millora de l'enunciat erroni dels alumnes (Chaudron, 1977). Lyster i Ranta (1997), en una recerca amb alumnes de primària en una classe d'immersió al Canadà, van identificar sis tipus de RCO: la reformulació, la correcció explícita, la pista metalingüística, la petició d'aclariment, l'elicitació i la repetició. Més tard, Ranta i Lyster (2007) van agrupar els tipus de RCO en represes (reformulations), aquelles intervencions del docent en què oferia la forma correcta, i en incitacions (prompts), aquelles correccions en què el docent intervenia amb la intenció d'animar l'alumne a autocorregir l'enunciat erroni (Taula 1).

A l'estudi de Lyster i Ranta (1997) la reformulació va ser el tipus de RCO que es va utilitzar més (en el 55\% dels casos), seguida per l'elicitació (14\%) i la petició d'aclariment (11\%). Els altres tres casos de RCO es van situar tots per sota del 10\%. Panova i Lyster (2002) van obtenir resultats semblants en unes classes d'anglès L2, en què la RCO més utilitzada va ser la reformulació (també un 55\%), seguida per la petició d'aclariment (11\%). La resta de casos de RCO es van situar també per sota del $10 \%$. La diferència principal entre els dos estudis va ser que a Panova i Lyster (2002) l'elicitació es va situar només en un 4\%, comparat amb un 14\% a Lyster i Ranta (1997). Lyster i Mori (2006) van analitzar la RCO en dos contextos de classes d'immersió diferents: un de japonès i un de francès. Van notar diferències en la relació entre els tipus de RCO i la resposta dels estudiants segons el context. En les classes de japonès va ser més freqüent la resposta després de les reformulacions, mentre que en el context de classes d'immersió en francès la resposta dels estudiants va ser més freqüent després de les incitacions. Fu i Nassaji (2016) van analitzar la interacció a l'aula durant unes classes de xinès com a llengua estrangera en un context universitari i van mostrar que el $56,7 \%$ eren reformulacions, el $10 \%$ consistia en pistes metalingüístiques $\mathrm{i}$ en diferents moments tots dos tipus de RCO es combinaven.

Quan els docents ofereixen RCO s'esperen una resposta (uptake) dels alumnes. D'acord amb Lyster i Ranta (1997), en aquest estudi definim resposta (uptake) com els diferents tipus d'enunciats dels alumnes produïts després de la RCO, i que inclou respostes amb reparació dels enunciats així com enunciats que encara presenten errors. També es pot donar el cas que l'alumne no tingui en compte la RCO i continuï amb el seu discurs.

Els resultats de les recerques que s'han centrat en la relació entre RCO, resposta i reparació dels alumnes són diversos. Algunes han mostrat que les reformulacions porten a menys respostes i reparacions dels estudiants que les incitacions (Lyster i Ranta, 1997; Panova i Lyster, 2002). Altres estudis han apuntat que les reformulacions poden ser efectives i conduir a un alt percentatge de respostes $(71,6 \%)$, de les quals $76,3 \%$ són de reparació (Ellis, Basturkmen i Loewen, 2001). A Fu i Nassaji (2016), l'alt nombre de reformulacions no va produir un alt percentatge de respostes $(49,6 \%)$ per part dels estudiants tot i que va portar a un $45,3 \%$ de reparacions. A Shirani (2019) els docents van utilitzar més les incitacions que les reformulacions. I les incitacions van proporcionar més oportunitats per a la resposta dels estudiants, tot i que 


\begin{tabular}{|c|c|c|c|}
\hline & Tipus de RCO & Definició & Exemple \\
\hline \multirow[t]{3}{*}{$\begin{array}{l}\text { Represes } \\
\text { (Reformulations) }\end{array}$} & $\begin{array}{l}\text { Reformulació } \\
\text { (Recast) }\end{array}$ & $\begin{array}{l}\text { El docent es limita a proporcionar } \\
\text { la forma correcta mentre reformula } \\
\text { l'enunciat de l'alumne. }\end{array}$ & $\begin{array}{l}\text { E: L'eau érable? } \\
\text { P: L'eau d'érable. C'est bien. } \\
\text { E: L'aigua auró. } \\
\text { P: L'aigua d'auró. Està bé. }\end{array}$ \\
\hline & $\begin{array}{l}\text { Correcció explícita } \\
\text { (Explicit correction) }\end{array}$ & $\begin{array}{l}\text { El docent proporciona la versió correcta } \\
\text { de la producció errònia però indica que } \\
\text { hi ha un problema. }\end{array}$ & $\begin{array}{l}\text { E: La note pour le shot. } \\
\text { P: Oh, pour la, oh, pour ça. } \\
\text { Tu veux dire pour la piquire. } \\
\text { Piqûre. Oui? }\end{array}$ \\
\hline & & & $\begin{array}{l}\mathrm{E}: \text { La nota per al shot. } \\
\mathrm{P}: \text { Oh, per a la, oh, per a això. Tu } \\
\text { vols dir la picada. Picada. Sí? }\end{array}$ \\
\hline
\end{tabular}

\section{Incitacions}

(Prompts)

Pista metalingüística
(Metalinguistic feedback)

El docent proporciona comentaris i preguntes o dona explicacions sobre la forma correcta a partir de l'error de l'alumne.

\section{Petició d'aclariment} (Clarification request)

El docent fa preguntes per entendre millor quan la producció de l'alumne no és comprensible.

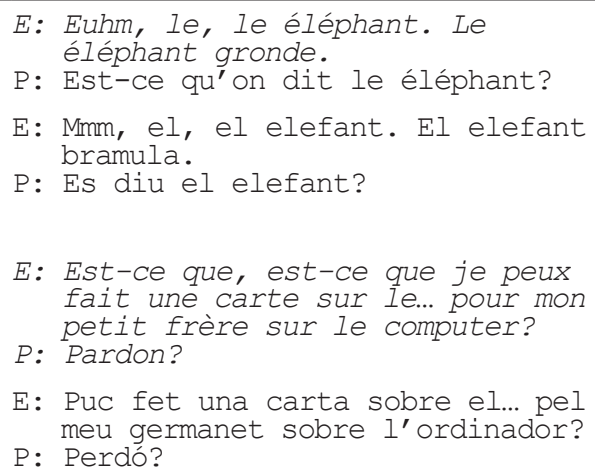

E: Est-ce que, est-ce que je peux fait une carte sur le... pour mon petit frère sur le computer?

E: Puc fet una carta sobre el... pel meu germanet sobre l'ordinador? P: Perdó?

E: Le chien peut court.

P: Le chien peut court? Le chien peut...

E: El gos pot corre.

P: El gos pot corre? El gos pot...

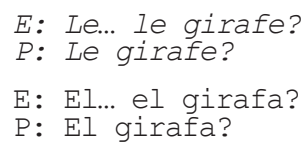

$\begin{array}{lll}\text { Repetició } & \text { El docent repeteix la producció de } & \text { E: Le... Ie girafe? } \\ \text { (Repetition) } & \text { l'alumne i emfasitza l'error amb } & \text { : Le girafe? } \\ & \text { entonació perquè l'alumne el noti i } & \text { E: El... el girafa? } \\ & \text { S'autocorregeixi. } & \text { P: El girafa? }\end{array}$

Taula 1. Tipus de RCO (adaptat de Lyster i Ranta (1997; 2007)

només en la meitat dels casos els va dur a la reparació. Les reformulacions, en canvi, van provocar un percentatge alt de reparacions $(74,5 \%)$, que no eren reparacions autogenerades sinó que eren repeticions de la RCO del docent.

\section{Retroacció correctiva oral amb alumnat adult poc escolaritzat}

U nombre considerable d'estudis han investigat la RCO oral amb alumnat adult poc escolaritzat, com el que s'estudia en aquest article. Bigelow, Delmas, Hansen i Tarone (2006) i Tarone i Bigelow (2007) van mostrar que, a diferència de l'alumnat alfabetitzat, l'alumnat poc escolaritzat processava el llenguatge en termes de significat i no de forma lingüística. Posteriorment, Tarone, Bigelow i Hansen (2009) van indicar que el nivell d'alfabetització estava relacionat amb un millor processament cognitiu de
${ }^{66}$ Els resultats de les recerques que s'han centrat en la relació entre $\mathrm{RCO}$, resposta i reparació dels alumnes són diversos. Algunes (recerques) han mostrat que les reformulacions porten a menys respostes $i$ reparacions dels estudiants que les incitacions. (Lyster i Ranta, 1997; Panova i Lyster, 2002). 
les característiques lingüístiques formals en la llengua oral necessàries per percebre $\mathrm{i}$ incorporar les reformulacions proporcionades pels docents. Bigelow, Delmas, Hansen i Tarone (2006) van replicar parcialment l'estudi que Philp (2003) havia realitzat amb alumnes universitaris en el qual havia investigat la RCO del docent $\mathrm{i}$ les respostes dels alumnes quan estudiaven la formulació de preguntes en anglès. Philp (2003) va concloure que les reformulacions eren més efectives quan la competència de l'alumne en la formulació de la pregunta es corresponia amb el nivell de les formes proporcionades en les reformulacions. Bigelow, Delmas, Hansen i Tarone (2006), en la seva rèplica, van comparar els resultats de dos grups d'alumnes, un amb un nivell d'alfabetització lleugerament més alt que l'altre, i van mostrar que el grup més alfabetitzat recordava les reformulacions significativament millor que el grup menys escolaritzat. A més, Tarone i Bigelow (2007) van assenyalar que els alumnes amb un nivell d'estudi baix utilitzaven més estratègies de tipus semàntic per processar les reformulacions $\mathrm{i}$ tenien dificultat per notar $\mathrm{i}$ repetir les reformulacions relacionades amb aspectes gramaticals (per ex. la inversió de l'ordre de les paraules en la pregunta Why he is mad? / Why is he mad?), ja que aquests canvis en l'ordre de les paraules no provocaven cap canvi en el significat de l'enunciat original. Segons Tarone (2021), l'absència o el coneixement limitat de la llengua escrita dificulta la capacitat dels alumnes per adonar-se de la RCO centrada en la forma i per assimilar-la.

En un context d'aula de neerlandès com a llengua addicional, Strube (2006) va observar tres tipus d'aula segons el grau d'alfabetització: 1) una aula en què els alumnes amb nivell d'alfabetització o habilitats orals semblants estaven separats en dos grups, un grup es dedicava a treballar les habilitats orals i l'altre l'alfabetització; 2) una aula en què tots els alumnes tenien un nivell d'alfabetització semblant $\mathrm{i}$ tots feien activitats per desenvolupar habilitats orals $i$ d'alfabetització; i 3) una aula en què el criteri de selecció es va basar en les característiques personals de les alumnes (totes dones, provinents del Marroc, amb com a mínim 6 anys de residència al país) $i$ on es feien activitats per desenvolupar habilitats orals i d'alfabetització. L'autora va analitzar les reformulacions, les respostes i les reparacions

\footnotetext{
${ }^{66}$ Tarone i Bigelow (2007) van assenyalar que els alumnes amb un nivell d'estudi baix utilitzaven més estratègies de tipus semàntic per processar les reformulacions (...)"
}

dels alumnes que apareixien a les converses entre docent $i$ alumnes i va mostrar que amb els alumnes poc alfabetitzats les reformulacions eren més efectives, és a dir, que conduïen els alumnes a reparar l'error, en activitats en les quals el focus era molt definit (com per exemple les activitats amb un focus lingüístic). En canvi, les reformulacions van generar menys reparació per part dels alumnes quan es tractava d'activitats més comunicatives en les quals la reformulació del docent podia centrar-se tant en aspectes d'ús de la llengua com en la forma lingüística.

En conclusió, els estudis previs han aportat resultats valuosos sobre els diferents tipus de RCO del docent i la resposta dels estudiants en contextos en què majoritàriament s'estudia l'anglès com a llengua addicional $\mathrm{i}$ amb alumnes amb alts graus d'escolarització. L'objectiu d'aquest estudi és ampliar la recerca en aquest àmbit a un context d'aprenentatge del català com a llengua addicional amb alumnes poc escolaritzats en seu penitenciària, un context en què l'exposició al català és limitada (Bretxa i Torner, 2005 i Barrionuevo, Cutillas i Torner, 2009). Les preguntes de recerca que guien aquest estudi són:

\section{- Quin és el tipus i la freqüència dels errors que produeixen els alumnes?}

\section{- Quina RCO proporciona la docent i amb quina freqüència?}

\section{- Quins efectes tenen els diferents tipus de RCO en la resposta dels alumnes?}

\section{Metodologia}

\subsection{Context de l'estudi}

7 estudi es va dur a terme en un grup de Formació Instrumental(FI) 2 d'un Centre de Formació d'Adults (CFA) en un centre penitenciari de Catalunya ${ }^{1}$. La FI s'articula en tres cursos: Formació Instrumental 1, 2 i 3. El curs de FI 1 és un curs d'alfabetització en què s'ensenyen les bases fonamentals de la lectura, l'escriptura i el càlcul així com nocions elementals de l'entorn social i natural. El curs de FI 2 té com a objectiu central consolidar aquests coneixements lingüístics, de càlcul i que expliquen l'entorn i, finalment, en el curs de FI 3 s'amplien els coneixements anteriors fins a assolir els objectius generals del cicle que poden permetre a l'alumnat cursar els estudis de Graduat en Educació Secundària Obligatòria (GESO) per a adults. La superació dels estudis de FI permet l'obtenció del certificat de Formació Instrumental.

Els participants van ser 13 alumnes de FI 2, tots homes i provinents del Marroc. Tenien un repertori lingüístic ampli, com també recull en el seu estudi Sans Bertran (2018), tot i que en l'àmbit penitenciari la llengua més utilitzada és 
el castellà (Bretxa i Torner, 2005; Barrionuevo, Cutillas i Torner, 2009). El seu repertori incloïa com a llengua inicial el dàrija (àrab marroquí) i coneixements de francès i castellà. Els alumnes tenien una edat compresa entre els 19 i els 23 anys. La docent, que és també autora d'aquest article, és catalanoparlant $\mathrm{i}$ té una experiència d'ensenyament en el centre de tres anys.

La metodologia del curs seguia un enfocament comunicatiu i la docent va mantenir la programació prevista sense cap canvi en funció de la recerca. En les sessions observades $\mathrm{i}$ analitzades, la docent va introduir un nou tema que tenia com a objectiu dotar els alumnes dels continguts lingüístics necessaris per parlar sobre l'àmbit de la feina. L'esquema de cada sessió d'aula era sempre el mateix. S'iniciava amb una conversa semiguiada en què la docent feia preguntes $i$ l'alumnat responia lliurement, sense haver d'utilitzar una determinada forma lingüística, que servia per introduir el tema de la sessió i despertar l'interès de l'alumne. Seguidament, els alumnes feien activitats que tenien un focus lingüístic, per exemple alguns aspectes de pronunciació, lèxic o gramàtica. En algun cas, es feien activitats de reconeixement del lèxic o de creació de petits diàlegs a partir d'un model.

\subsection{Recollida i tractament de les dades}

Per qüestions ètiques, abans de començar la recollida de les dades es va demanar el consentiment a la direcció del centre penitenciari, a la direcció del CFA i a tots els alumnes que van participar en l'estudi. Les dades es van recollir de l'11 al 15 de gener de 2021 durant un total de cinc sessions d'uns 45-50 minuts cadascuna. Les sessions es van enregistrar en àudio, ja que no es va obtenir el permís de fer la gravació en vídeo i per tant no tenim accés a aspectes no verbals. Les gravacions es van transcriure completament segons les convencions de van Lier (1988) ${ }^{2}$ i van generar un total de 1.336 torns de paraula, dels quals 764 són de la docent i 572 dels alumnes.

Les dues autores del treball van codificar totes les dades de manera independent. En un segon moment van comparar els resultats de la codificació, que va coincidir en un $90 \%$, i van discutir juntes les diferències per arribar a un acord per al 10\% restant. Segons Miles i Huberman (1994) la fiabilitat entre els avaluadors ha d'aproximar-se o superar el $90 \%$. En aquest estudi la fiabilitat es va estimar amb la fórmula "Acord/Acord+Desacord" i el nivell d'acord a què es va arribar entre les investigadores és alt: 187/187+19=0,91.

\subsection{Codificació dels errors}

Vázquez $(1992,1999)$ proposa una classificació dels errors dels estudiants durant el procés d'aprenentatge de l'espanyol com a llengua estrangera seguint 6 criteris: gramatical, descriptiu, pedagògic, etiològic, comunicatiu i cultural. Dins del criteri gramatical, l'autora diferencia entre errors fonològics, ortogràfics, lèxics, sintàctics, morfosintàctics, semàntics i pragmàtics.

Per a la codificació dels errors d'aquest estudi es va adoptar el criteri gramatical de Vázquez (1992) i, seguint els estudis de Ferreira (2006) i Bao (2019), es van classificar en 4 categories: pronunciació, lèxic, gramatical i múltiple.

Pel que fa als errors de pronunciació es van documentar l'accentuació tònica inapropiada i la pronunciació errònia de les paraules en català (Exemple 1):

\section{Exemple 1}

1. E: la pintora pinta ['parets] ['parets]

2. P: molt bé! la pintora pinta [pa're: :ts]

En el cas dels errors de tipus lèxic, es van tenir en compte el desconeixement de la paraula i l'ús inadequat o imprecís del terme lèxic (Exemple 2):

\section{Exemple 2}

1. E: vetenario vetenario de: ("vetenario" en lloc de veterinari)

2. P: veterinari aquest els que cuiden els que curen els animals

Quant als errors gramaticals, es van considerar els errors en l'estructura de la frase, de la conjugació dels verbs, i de la concordança de tres tipus: subjecte/verb, substantiu/adjectiu i determinant/substantiu (Exemple 3):

\section{Exemple 3}

$\mathrm{E}$ : quin imatge corresponde al ofici de co- de coci- de cu- cuina cocina ("quin imatge" en lloc de "quina imatge")

Pel que fa als errors múltiples es van examinar tots els casos que reunien més d'un tipus d'errors en la producció de l'alumne (Exemple 4):

\section{Exemple 4}

E: [ta'Ker] [ta'Ker] [ta'Ker] no? exacto? (ús inadequat de la paraula "taller" en lloc de "tallar" i pronunciació errònia)

Finalment, es van afegir dos nous tipus d'error: "ús no sol·licitat del castellà com a llengua d'ús comú" i "ús no sol·licitat del francès com a llengua addicional". A diferència de Jimenez (2006), els alumnes del nostre estudi a l'aula no utilitzen la seva L1, el dàrija, sinó que utilitzen la llengua que comparteixen amb la docent (el castellà) o utilitzen el francès com a llengua addicional, que comparteixen amb els altres companys i que és una llengua pròxima al català. Així doncs, les dues noves categories d'errors es refereixen a tots els casos en què els estudiants van utilitzar el castellà $i$ el francès quan s'esperaria que haguessin utilitzat el català com a llengua d'aprenentatge (Exemple 5): 


\section{Exemple 5}

1. P: quins oficis vam treballar va! digueu-me el nom!

2. E: carpintero médico médico:

D'acord amb Lyster (1998) i Jimenez (2006), no es van classificar dins d'aquest tipus d'errors els casos d'ús del castellà com a resposta a una demanda de la docent (Exemple 6), quan els alumnes demanaven un aclariment a la docent (Exemple 7), els enunciats per gestionar la tasca (Exemple 8) o per fer algun comentari que no estava relacionat amb l'activitat (Exemple 9):

\section{Exemple 6}

1. P: què vol dir ven?

2. E: ven?

3. $\mathrm{P}:$ ven

4. E: que trabaja: en: de camarero

\section{Exemple 7}

E: el caball es diu: professora! el cabell com es diu? es cortar?

\section{Exemple 8}

E: cada foto le ponemos un número ahí

\section{Exemple 9}

E: mecànic esta profesora enseña muy bien ((dient-ho a la gravadora))

\begin{tabular}{|c|c|c|}
\hline Tipus de RCO & Definició & Exemple \\
\hline $\begin{array}{l}\text { Reformulació immediata } \\
\text { (Immediate recast) }\end{array}$ & $\begin{array}{l}\text { El docent proporciona la forma correcta reformulant } \\
\text { l'enunciat. }\end{array}$ & $\begin{array}{l}\text { 1. E: vividor vindidor } \\
\text { 2. } \mathrm{P} \text { : venedor } \\
\text { 3. E: venedor }\end{array}$ \\
\hline $\begin{array}{l}\text { Reformulació diferida } \\
\text { (Delayed recast) }\end{array}$ & $\begin{array}{l}\text { El docent reformula l'enunciat que conté l'error de l'alumne } \\
\text { amb una mica de retard. }\end{array}$ & $\begin{array}{l}\text { 1. E: quinze a policia(.) qué } \\
\text { imatge corresponde a } \\
\text { l'oficina yo he post al = } \\
\text { 2. P: no: } \\
\text { 3. E: = imatge } \\
\text { 4. P: no: : quina imatge correspon } \\
\text { a l'ofici de: } \\
\text { 5. E: la policia! }\end{array}$ \\
\hline $\begin{array}{l}\text { Petició d'aclariment } \\
\text { (Clarification request) }\end{array}$ & $\begin{array}{l}\text { El docent fa preguntes per entendre millor la producció no } \\
\text { comprensible de l'alumne, sense proporcionar la forma } \\
\text { correcta. }\end{array}$ & $\begin{array}{l}\text { 1. E: jaima las mantas: XXX } \\
\text { 2. P: ah:: com has dit? }\end{array}$ \\
\hline $\begin{array}{l}\text { Pista metalingüística } \\
\text { (Metalinguistic feedback) }\end{array}$ & $\begin{array}{l}\text { El docent proporciona comentaris, fa preguntes o dona } \\
\text { explicacions sobre la forma correcta a partir de l'error de } \\
\text { l'alumne. }\end{array}$ & $\begin{array}{l}\text { 1. P: què vol dir ven? } \\
\text { 2. E: ven? } \\
\text { 3. P: ven } \\
\text { 4. E: que trabaja: en: de camarero } \\
\text { 5. P: no: } \\
\text { 6. E: XXX } \\
\text { 7. P: no: : ven ve del verb vendre: }\end{array}$ \\
\hline $\begin{array}{l}\text { Elicitació } \\
\text { (Elicitation) }\end{array}$ & $\begin{array}{l}\text { El docent no proporciona la forma correcta, sinó que invita } \\
\text { l'alumne a autocorregir la producció errònia. }\end{array}$ & $\begin{array}{l}\text { 1. P: com es diu? } \\
\text { 2. E: soldadura }\end{array}$ \\
\hline $\begin{array}{l}\text { Correcció explícita } \\
\text { (Explicit correction) }\end{array}$ & $\begin{array}{l}\text { El docent proporciona la versió correcta de la producció } \\
\text { errònia però indicant que hi ha un problema. }\end{array}$ & $\begin{array}{l}\text { 1. E: camionero } \\
\text { 2. P: camioner en català }\end{array}$ \\
\hline $\begin{array}{l}\text { Repetició } \\
\text { (Repetition) }\end{array}$ & $\begin{array}{l}\text { El docent repeteix la producció de l'alumne emfasitzant } \\
\text { l'error amb l'entonació perquè l'alumne el noti i } \\
\text { s'autocorregeixi. }\end{array}$ & $\begin{array}{l}\text { 1. E: no! chapista } \\
\text { 2. P: és chapista? }\end{array}$ \\
\hline $\begin{array}{l}\text { Traducció } \\
\text { (Translation) }\end{array}$ & $\begin{array}{l}\text { El docent proporciona una traducció en la llengua meta } \\
\text { d'un enunciat expressat en la llengua d'ús comú del grup, } \\
\text { el castellà. }\end{array}$ & $\begin{array}{l}\text { 1. E: trabaja en el campo } \\
\text { 2. P: treballa al camp }\end{array}$ \\
\hline $\begin{array}{l}\text { Pregunta directa } \\
\text { (Asking a direct question) }\end{array}$ & $\begin{array}{l}\text { El docent fa una pregunta directament a l'alumne al } \\
\text { voltant d'una determinada forma o expressió en la llengua } \\
\text { meta (per ex. "com es diu això en català?"). S’assembla } \\
\text { a l'elicitació i l'objectiu és incitar l'alumne que intenti } \\
\text { novament de produir la forma de manera correcta. }\end{array}$ & $\begin{array}{l}\text { 1. E: profesores de deporte: } \mathbf{e :} \\
\text { física } \\
\text { 2. P: en català com ho diries } \\
\text { això? } \\
\text { 3. E: esport profes- esport } \\
\text { profesores esport }\end{array}$ \\
\hline
\end{tabular}

Taula 2. Codificació dels tipus de RCO (adaptat de Fu i Nassaji, 2016) 


\begin{tabular}{|c|c|c|}
\hline Tipus de resposta dels estudiants & Definició & Exemple \\
\hline $\begin{array}{l}\text { Amb èxit } \\
\text { (Successful uptake) }\end{array}$ & $\begin{array}{l}\text { L'alumne nota l'error i el repara després } \\
\text { de la retroacció del docent. }\end{array}$ & $\begin{array}{l}\text { 1. P : vale! què són tot això que esteu } \\
\quad \text { dient? } \\
\text { 2. E1: /trabajos/ } \\
\text { 3. E2: /trabajadores/ } \\
\text { 4. P : treballadors? treballs? } \\
\text { 5. E1: treballadors }\end{array}$ \\
\hline $\begin{array}{l}\text { Sense èxit } \\
\text { (Unsuccessful uptake) }\end{array}$ & $\begin{array}{l}\text { Hi ha una reacció verbal de l'alumne, } \\
\text { però la reparació és parcial o no respon } \\
\text { a l'objectiu. }\end{array}$ & $\begin{array}{l}\text { 1. E1: comptabilité no sé como se dice } \\
\text { 2. } \mathrm{P} \text { : ah! un comptable } \\
\text { 3. } \mathrm{E} 1 \text { : eso sí } \\
\text { 4. } \mathrm{P} \text { : una persona que fa comptes } \\
\text { 5. E2: / sí/ }\end{array}$ \\
\hline $\begin{array}{l}\text { Sense resposta } \\
\text { (No uptake) }\end{array}$ & $\begin{array}{l}\text { L'alumne no reacciona verbalment } \\
\text { a la RCO del docent. }\end{array}$ & $\begin{array}{l}\text { 1. P : quins oficis més trobem aquí al centre } \\
\text { penitenciari? } \\
\text { 2. E1: funcionarios } \\
\text { 3. P : funcionari:s què més? } \\
\text { 4. E2: porteros } \\
\text { 5. E3: educadore:s } \\
\text { 6. P : educadors molt bé } \\
\text { 7. E3: trabajadores sociales } \\
\text { 8. E1: psi-ps-i psi- psicólogos } \\
\text { 9. E3: psicólogas } \\
\text { 10.P : molt bé! psicòlegs }\end{array}$ \\
\hline
\end{tabular}

Taula 3. Codificació del tipus de resposta dels estudiants (adaptat de Fu i Nassaji, 2016)

\subsection{Codificació dels tipus de RCO}

La codificació dels diferents tipus de RCO es va basar en la classificació de Fu i Nassaji (2016). A la Taula 2 s'ofereix una explicació de cada tipus de RCO de la taxonomia de $\mathrm{Fu}$ i Nassaji (2016) amb un exemple per a cada cas extret de les dades recollides. Cal notar que de la classificació de Fu i Nassaji (2016) se'n van excloure els següents tipus de RCO: preguntar de nou, preguntar a un altre estudiant i ús de la L1, ja que no se'n va documentar cap cas a les dades del nostre estudi.

\subsection{Codificació del tipus de resposta dels estudiants}

Per codificar la resposta (uptake) dels estudiants ens vam basar en Fu i Nassaji (2016) i vam distingir entre resposta dels estudiants amb èxit, sense èxit i sense resposta. La Taula 3 dona una definició i un exemple per a cada tipus de resposta.

\section{Resultats}

A les dades de l'estudi es van detectar 287 errors en total. A la Taula 4 es pot veure que la majoria dels errors van ser els relacionats amb l'ús no sol·licitat del castellà com a llengua d'ús comú $(41,5 \%)$ en un moment en el qual s'hauria esperat que els alumnes utilitzessin el català. Els errors de pronunciació van ser el 24,0\%, seguits dels errors de lèxic $(17,4 \%)$. Els errors gramaticals, els errors múltiples i l'ús no sol·licitat del francès com a llengua addicional es van situar tots per sota del 10\%.

\begin{tabular}{lcc}
\hline Tipus d'error & Freqüència $\mathbf{n}$ & Freqüència \% \\
\hline Ús no sol·licitat del castellà & 119 & $41,5 \%$ \\
Errors de pronunciació & 69 & $24,0 \%$ \\
Errors de lèxic & 50 & $17,4 \%$ \\
Errors gramaticals & 25 & $8,7 \%$ \\
Errors múltiples & 19 & $6,6 \%$ \\
Ús no sol·licitat del francès & 5 & $1,7 \%$ \\
\hline Total & $\mathbf{2 8 7}$ & $\mathbf{1 0 0} \%$ \\
\hline
\end{tabular}

Taula 4. Freqüència de tipus d'error

La Taula 5 mostra que en la majoria dels casos $(34,8 \%)$ els alumnes no van rebre cap tipus de RCO. La decisió de la docent de no proporcionar RCO va dependre principalment del fet que els enunciats incloïen més d'un error i que la docent va optar per resoldre'n només un, generalment l'últim. En l'exemple 10, l'alumne en el torn 1 va fer un ús no sol·licitat del castellà com a llengua d'ús comú ("imagen corresponde"), un error lèxic ("oficina" en lloc "d'ofici") i un error de pronunciació (['tat $\left.\left.\int i\right]\right)$. En aquest cas, la docent, a través d'una petició d'aclariment, va portar l'alumne a centrar l'atenció en la pronunciació de la paraula "taxista": 


\section{Exemple 10}

1. E: quina imagen corresponde a la oficina de ['tat $\left.\int i\right]$ ['tat $\left.\int i\right]$

2. P: però espera de què?

3. E: taxista

En altres casos la docent va focalitzar la seva atenció en el funcionament de l'activitat i va prioritzar la comprensió del significat de la paraula per part dels alumnes. En l'exemple 11, la docent no va considerar els errors de pronunciació en l'enunciat del torn 3 i va confirmar (torn 4) la relació entre la imatge i la paraula que li corresponia:

\section{Exemple 11}

1. P: no ara professor no: : que professor ja ho sabem haurem de posar paleta no?

2. E1: paleta sí

3. E2: jo he ['post] la [i'maxe] ca

4. P: ca! molt bé! aleshores sabem que paleta: :és

Els altres tipus de RCO més freqüents van ser les reformulacions i les traduccions (Taula 5). Concretament, el $23 \%$ dels casos de RCO van ser reformulacions immediates, el $16,7 \%$ van ser traduccions, i les reformulacions diferides van representar un 7,7\%. La docent, a través de la RCO, va proporcionar les respostes correctes als alumnes i només un $17,8 \%$ van ser RCO que incitaven l'alumne a corregir el seu propi error. Dins d'aquest segon grup, la petició d'aclariment va ser el tipus de RCO més freqüent (5,6\%), seguit per l'elicitació (4,9\%). Tots els altres tipus de RCO es van situar per sota del $5 \%$ del total.

\begin{tabular}{lcc}
\hline Tipus RCO & Freqüència n & Freqüència $\%$ \\
\hline Sense RCO & 100 & $34,8 \%$ \\
Reformulació immediata & 66 & $23,0 \%$ \\
Traducció & 48 & $16,7 \%$ \\
Reformulació diferida & 22 & $7,7 \%$ \\
Petició d'aclariment & 16 & $5,6 \%$ \\
Elicitació & 14 & $4,9 \%$ \\
Correcció explícita & 8 & $2,8 \%$ \\
Pregunta directa & 6 & $2,1 \%$ \\
Repetició & 4 & $1,4 \%$ \\
Pista metalingüística & 3 & $1,0 \%$ \\
\hline Total & $\mathbf{2 8 7}$ & $\mathbf{1 0 0} \%$ \\
\hline
\end{tabular}

Taula 5. Freqüència de cada tipus de RCO

La Taula 6 presenta les freqüències i les relacions entre el tipus d'error de les produccions de l'alumnat i el tipus de RCO proporcionat per la docent. En total, la docent va proporcionar 187 correccions orals (65,2\% dels errors comesos, 287 en total). Els errors que van rebre RCO més freqüentment van ser els que impliquen l'ús no sol·licitat del castellà llengua d'ús comú $(70,6 \%)$, que també van ser els més freqüents. Un $16,7 \%$ del total dels errors va rebre RCO per traducció. Els errors de pronunciació van rebre RCO en un 39,1\% dels casos i es va fer a partir de reformulacions immediates. En un $10,1 \%$ dels casos els errors de pronunciació es van corregir amb reformulacions diferides. La RCO en resposta als errors

\begin{tabular}{|c|c|c|c|c|c|c|c|c|c|c|c|c|c|c|}
\hline \multirow[t]{2}{*}{ Tipus de RCO } & \multicolumn{2}{|c|}{$\begin{array}{c}\text { Ús no } \\
\text { sol·licitat del } \\
\text { castellà com } \\
\text { a llengua } \\
\text { d'ús comú }\end{array}$} & \multicolumn{2}{|c|}{$\begin{array}{c}\text { Error } \\
\text { pronuncia- } \\
\text { ció }\end{array}$} & \multicolumn{2}{|c|}{$\begin{array}{l}\text { Error } \\
\text { lèxic }\end{array}$} & \multicolumn{2}{|c|}{$\begin{array}{c}\text { Error } \\
\text { gramatical }\end{array}$} & \multicolumn{2}{|c|}{$\begin{array}{c}\text { Error } \\
\text { múltiple }\end{array}$} & \multicolumn{2}{|c|}{$\begin{array}{c}\text { Ús no } \\
\text { sol·licitat del } \\
\text { francès com } \\
\text { a llengua } \\
\text { addicional }\end{array}$} & \multicolumn{2}{|c|}{ Total } \\
\hline & $\mathrm{n}$ & $\%$ & $\mathrm{n}$ & $\%$ & $\mathrm{n}$ & $\%$ & $\mathrm{n}$ & $\%$ & $\mathrm{n}$ & $\%$ & $\mathrm{n}$ & $\%$ & $\mathrm{n}$ & $\%$ \\
\hline Sense RCO & 35 & 29,4 & 25 & 36,2 & 21 & 42,0 & 17 & 68,0 & 1 & 5,3 & 1 & 20,0 & 100 & 34,8 \\
\hline Reformulació immediata & 11 & 9,2 & 27 & 39,1 & 12 & 24,0 & 3 & 12,0 & 12 & 63,2 & 1 & 20,0 & 66 & 23,0 \\
\hline Traducció & 44 & 37,0 & 0 & 0 & 0 & 0,0 & 0 & 0,0 & 1 & 5,3 & 3 & 60,0 & 48 & 16,7 \\
\hline Reformulació diferida & 10 & 8,4 & 7 & 10,1 & 2 & 4,0 & 1 & 4,0 & 2 & 10,5 & 0 & 0 & 22 & 7,7 \\
\hline Petició aclariment & 6 & 5,0 & 4 & 5,8 & 4 & 8,0 & 1 & 4,0 & 1 & 5,3 & 0 & 0 & 16 & 5,6 \\
\hline Elicitació & 3 & 2,5 & 3 & 4,3 & 6 & 12,0 & 2 & 8,0 & 0 & 0 & 0 & 0 & 14 & 4,9 \\
\hline Correcció explícita & 2 & 1,7 & 1 & 1,4 & 4 & 8,0 & 0 & 0 & 1 & 5,3 & 0 & 0 & 8 & 2,8 \\
\hline Pregunta directa & 6 & 5,0 & 0 & 0,0 & 0 & 0,0 & 0 & 0 & 0 & 0 & 0 & 0 & 6 & 2,1 \\
\hline Repetició & 1 & 0,8 & 1 & 1,4 & 1 & 2,0 & 1 & 4,0 & 0 & 0 & 0 & 0 & 4 & 1,4 \\
\hline Pista metalingüística & 1 & 0,8 & 1 & 1,4 & 0 & 0 & 0 & 0 & 1 & 5,3 & 0 & 0 & 3 & 1,0 \\
\hline Total & 119 & 100,0 & 69 & 100,0 & 50 & 100,0 & 25 & 100,0 & 19 & 100,0 & 5 & 100,0 & 287 & 100,0 \\
\hline
\end{tabular}

Taula 6. Freqüències i relació entre el tipus de RCO i el tipus d'error 
gramaticals, múltiples i d'ús no sol·licitat del francès llengua addicional és poc informativa, ja que el nombre d'errors se situa per sota del $10 \%$. Cal destacar que el $68 \%$ dels errors gramaticals no van rebre cap tipus de RCO.

Pel que fa als efectes dels diferents tipus de RCO en la resposta dels alumnes després de la intervenció de la docent, en el 32,3\% dels casos els estudiants la van incorporar amb èxit i van corregir l'error (Taula 7). En el 32,8\% dels casos, els alumnes van agafar el torn, però no van aconseguir reparar l'error o el van reparar parcialment. En la resta de casos $(34,9 \%)$, no hi va haver cap intent dels alumnes d'incorporar la correcció proposada per la docent.

\begin{tabular}{lcc}
\hline Tipus de resposta dels estudiants & Freqüència $\mathbf{n}$ & Freqüència $\%$ \\
\hline Amb èxit & 61 & $32,3 \%$ \\
Sense èxit & 62 & $32,8 \%$ \\
Sense resposta & 64 & $34,9 \%$ \\
\hline Total & $\mathbf{1 8 7}$ & $\mathbf{1 0 0 \%}$ \\
\hline
\end{tabular}

Taula 7. Tipus i freqüència de les respostes dels estudiants

A la Taula 8, es recullen les relacions entre els diferents tipus de RCO utilitzats per la docent i la resposta dels alumnes.

L'alt nombre de les reformulacions immediates i diferides $(n=88)$ va fer que la majoria de les respostes dels estudiants estiguessin relacionades amb aquests dos tipus de RCO.
Quant a les respostes dels alumnes davant les reformulacions hi va haver, però, una diferència de tendència entre les reformulacions immediates i les diferides. Les reformulacions immediates van provocar un $37,9 \%$ de reparacions, mentre que, en les reformulacions diferides, només un 18,2\% va portar els alumnes a corregir l'error en el seu enunciat. Les reformulacions diferides van ser el tipus de RCO que va presentar un percentatge més elevat de casos sense resposta $(59,1 \%)$.

Tot i no ser un dels tipus més freqüents, l'elicitació va ser la RCO que proporcionalment va conduir més els alumnes a reparar l'error, concretament, en el $50 \%$ dels casos. La traducció, tot i que va ser el segon tipus de RCO més freqüent entre els que va utilitzar la docent $(16,7 \%)$, en el $44,9 \%$ dels casos no va portar els alumnes a la reparació i només en el 30,6\% dels casos els alumnes van reparar l'enunciat expressat en l'ús no sol·licitat del castellà com a llengua d'ús comú.

La petició d'aclariment, tot i ser el quart tipus de RCO més utilitzat, no va ser un tipus de RCO gaire efectiu . De fet, en el $62,5 \%$ dels casos no va portar els alumnes a la reparació. Els altres tipus de RCO (correcció explícita, pregunta directa, repetició i pista metalingüística) van aparèixer en ocasions molt limitades i per això són poc informatius. Tanmateix, l'ús de la correcció explícita i la pista metalingüística apunten a una tendència de reparació. En canvi, la repetició i la pregunta directa podien ser percebudes com a estratègies discursives i no correctives i, per tant, no van atraure l'atenció dels alumnes.

\begin{tabular}{|c|c|c|c|c|c|c|c|c|c|c|}
\hline \multirow[t]{2}{*}{ Tipus de RCO } & \multicolumn{2}{|c|}{$\begin{array}{l}\text { Resposta dels } \\
\text { estudiants } \\
\text { amb èxit }\end{array}$} & \multicolumn{2}{|c|}{$\begin{array}{l}\text { Resposta dels } \\
\text { estudiants } \\
\text { sense èxit }\end{array}$} & \multicolumn{2}{|c|}{$\begin{array}{l}\text { Total } \\
\text { resposta dels } \\
\text { estudiants }\end{array}$} & \multicolumn{2}{|c|}{$\begin{array}{l}\text { Sense } \\
\text { resposta }\end{array}$} & \multicolumn{2}{|c|}{ Total } \\
\hline & $\mathrm{n}$ & $\%$ & $\mathrm{n}$ & $\%$ & $\mathrm{n}$ & $\%$ & $\mathrm{n}$ & $\%$ & $\mathrm{n}$ & $\%$ \\
\hline Reformulació immediata & 25 & 37,9 & 20 & 30,3 & 45 & 68,2 & 21 & 31,8 & 66 & 100,0 \\
\hline Traducció & 15 & 30,6 & 12 & 24,5 & 27 & 55,1 & 21 & 44,9 & 48 & 100,0 \\
\hline Reformulació diferida & 4 & 18,2 & 5 & 22,7 & 9 & 40,9 & 13 & 59,1 & 22 & 100,0 \\
\hline Petició aclariment & 3 & 18,8 & 10 & 62,5 & 13 & 81,3 & 3 & 18,8 & 16 & 100,0 \\
\hline Elicitació & 7 & 50,0 & 5 & 35,7 & 12 & 85,7 & 2 & 14,3 & 14 & 100,0 \\
\hline Correcció explícita & 4 & 50,0 & 2 & 25,0 & 6 & 75,0 & 2 & 25,5 & 8 & 100,0 \\
\hline Pregunta directa & 1 & 14,3 & 4 & 57,1 & 5 & 71,4 & 1 & 28,6 & 6 & 100,0 \\
\hline Repetició & 0 & 0,0 & 4 & 100,0 & 4 & 100,0 & 0 & 0,0 & 4 & 100,0 \\
\hline Pista metalingüística & 2 & 66,7 & 0 & 0,0 & 2 & 66,7 & 1 & 33,3 & 3 & 100,0 \\
\hline Total & 61 & 32,3 & 62 & 32,8 & 123 & 65,1 & 64 & 34,9 & 187 & 100,0 \\
\hline
\end{tabular}

Taula 8. Relació entre el tipus de RCO i la resposta dels estudiants 


\section{Discussió}

a primera pregunta de recerca d'aquest estudi se centrava a identificar els diferents tipus d'error i la seva freqüència. Dels 287 casos d'errors que es van obtenir, el $41,5 \%$ va correspondre a l'ús no sol-licitat del castellà com a llengua d'ús comú, a diferència de Lyster (1998), que va documentar un $16 \%$ de casos, i de Jimenez (2006), en què els casos de L1 no sol-licitada van ser molt limitats (menys del 10\% en els dos grups). Seguint Vila, Sorolla i Larrea (2013), l'ús del castellà per part dels participants del nostre estudi es pot relacionar amb diferents factors. D'una banda, habitualment les persones marroquines que arriben a Catalunya prioritzen l'aprenentatge del castellà, idioma que predomina en l'àmbit laboral on s'incorporen. D'altra banda, hi ha la norma de subordinació del català enfront de la llengua de l'Estat, imposada al llarg del segle $\mathrm{XX}$ per les polítiques lingüístiques públiques. Finalment, les persones marroquines presenten unes trajectòries migratòries que els porta a seguir la feina en diferents zones d'Espanya seguint amistats o família que els poden acollir i proporcionar habitatge i contactes laborals. Altres autors posen en evidència que en el context penitenciari el castellà és la llengua que s'utilitza de manera més freqüent i aquest fet té una influència en l'ús del català (Bretxa i Torner, 2005; Barrionuevo, Cutillas i Torner, 2009; Sans Bertran, 2018, Birello, Pérez Ventayol i Casadellà Matamoros, 2017).

La segona pregunta se centrava en el tipus i la freqüència de la RCO proporcionada per la docent. Quan els alumnes van emprar el castellà, en lloc de fer servir el català, la docent va proporcionar RCO en el 70,6\% dels casos. El tipus de RCO més utilitzat va ser la traducció al català (37\%). Aquest resultat marca una diferència important amb l'estudi de Fu i Nassaji (2016), en què la traducció se situava en només un $7,3 \%$ de la RCO proporcionada per la docent. Com a Fu i Nassaji (2016), al nostre estudi la docent tenia la intenció d'encoratjar els alumnes a fer ús de la llengua meta, i el

\section{${ }^{66}$ La primera pregunta de recerca d'aquest estudi se centrava a identificar els diferents tipus d'error i la seva freqüència. Dels 287 casos d'errors que es van obtenir, el $41,5 \%$ va correspondre a l'ús no sol-licitat del castellà com a llengua d'ús comú"}

percentatge molt més elevat de casos es pot explicar amb la voluntat de promocionar l'ús del català, llengua minoritària davant de l'ús preferent de l'altra llengua cooficial, el castellà que, tal com ja s'ha esmentat, és molt més present en l'àmbit penitenciari.

Igual que en altres estudis, la majoria de les RCO del nostre estudi van correspondre a les reformulacions (47,1\%) (Lyster i Ranta, 1997; Lyster, 1998; Panova i Lyster, 2002; Lyster i Mori, 2006; Jimenez, 2006; Fu i Nassaji, 2016). Aquest resultat apunta a una tendència de la docent a proporcionar una RCO més implícita, amb la intenció de facilitar més mostres de llengua meta a un col·lectiu que tenia poques possibilitats de sentir-la i utilitzar-la. Cal destacar que els errors gramaticals, tot i ser un tipus d'error poc freqüent $(8,7 \%)$, només van rebre RCO en un $32 \%$. Aquest resultat es pot relacionar amb dos fets. D'una banda, la majoria de les activitats d'aula tenien un focus lèxic i per tant la docent va prioritzar la correcció d'aquest tipus d'error. D'altra banda, els alumnes poc escolaritzats tenen dificultats per reparar errors centrats en la forma, tal com han indicat estudis anteriors (Tarone, Bigelow i Hansen, 2009).

Cal destacar que en el 34,8\% dels casos d'errors no es va proporcionar cap tipus de RCO. Aquest fet s'explica perquè molts enunciats contenien més d'un error i es va prioritzar un tipus concret d'errors que en la majoria dels casos eren errors de pronunciació o lèxic. En algun cas, es va prioritzar la correcció en funció de la posició en què l'error apareixia en l'enunciat produït pels alumnes, $i$ en aquest cas es va tendir a corregir l'error que es trobava al final. Entre les represes, la correcció explícita es va utilitzar d'una manera molt esporàdica, només un 4,5\%. Molt probablement això depèn del fet que la correcció explícita, a diferència de la reformulació i de les incitacions, indica més clarament que l'alumne s'ha equivocat i la docent va preferir utilitzar un tipus de RCO que estimulés la participació de l'alumnat per evitar casos d'inhibició adulta (Fernández López, 1995).

La tercera pregunta de recerca de l'estudi tenia com a objectiu indagar sobre quins efectes tenien els diferents tipus de RCO en la resposta dels alumnes. La reacció dels alumnes davant la RCO va ser bastant repartida entre les respostes amb èxit $(32,3 \%)$, sense èxit $(32,8 \%)$ i sense resposta $(34,9 \%)$. En el 65\% dels casos, els alumnes van percebre la RCO proporcionada, però només en un $32,3 \%$ dels casos hi va haver reparació. Igual que a Strube (2006), amb els alumnes poc escolaritzats, les reformulacions van ser efectives, tot $i$ que es podria tractar d'una repetició (Shirani, 2019) sense que hi hagi una comprensió real de la diferència entre l'enunciat produït i la mostra de llengua meta proporcionada pel docent. Això explicaria la reincidència apreciada en el corpus de determinades formes errònies fins i tot després de la intervenció, de vegades reiterada sobre el mateix contingut, de la docent. En aquest sentit, es necessiten més recerques. En el nostre estudi, les reformulacions més efectives van ser les immediates, ja que els estudiants les percebien en el 68,2\% dels casos i en el 37,9\% portaven a la reparació. En canvi, el cas de les reformulacions diferides va ser lleugerament diferent, ja que van semblar menys efectives pel fet que 
${ }^{66}$ La majoria de les activitats d'aula tenien un focus lèxic i per tant la docent va prioritzar la correcció d'aquest tipus d'error.

\author{
D'altra banda, els alumnes \\ poc escolaritzats tenen \\ dificultats per reparar errors \\ centrats en la forma, tal com \\ han indicat estudis anteriors \\ (Tarone, Bigelow i Hansen, \\ 2009).'
}

només en un 18,2\% dels casos van desembocar en reparació. Cal destacar que la reformulació diferida va ser el tipus de RCO que tenia el percentatge més alt de casos sense resposta per part dels alumnes $(59,1 \%)$. Una explicació d'aquest resultat pot ser que quan es va proporcionar la RCO de manera diferida l'alumne estava concentrat en altres tasques i no va percebre la RCO de la docent com una correcció a un error que havia produït anteriorment.

Com va passar amb les reformulacions, la traducció al català per part de la docent dels enunciats en castellà dels alumnes va ser un tipus de RCO poc efectiu, ja que va portar els alumnes a la reparació en només un $30,9 \%$ i, en la majoria dels casos (44,9\%), es va quedar sense resposta de l'alumnat. La traducció és una manera d'aportar nou input a l'alumnat, però els alumnes no el van percebre com una correcció i per tant no es van autocorregir.

Cal destacar que, encara que no es tracti de tipus de RCO molt freqüents, la petició d'aclariment i l'elicitació van provocar una resposta per part dels alumnes en un $81,3 \%$ $i$ en un $85,7 \%$ dels casos, respectivament. En aquest sentit, es mostra una tendència amb els alumnes poc alfabetitzats similar a la que Fu i Nassaji (2016) van detectar amb alumnes universitaris. Pel que fa a la reparació, els alumnes poc escolaritzats van tenir un comportament diferent: la meitat dels casos d'elicitació va portar a la reparació, en canvi, la petició d'aclariment no va ser tan efectiva, ja que en la majoria dels casos $(62,5 \%)$ no va portar els alumnes a reparar l'error. Això pot dependre del fet que l'alumnat del nostre estudi no va percebre la petició d'aclariment com una estratègia correctiva sinó com una estratègia discursiva. En aquest sentit, són necessàries més recerques.

Finalment, encara que siguin pocs casos, sembla que hi va haver una tendència a la reparació quan la docent va utilitzar un tipus de RCO més explícit, que guiava més els alumnes a la reparació com, per exemple, la correcció explícita, l'elicitació i la pista metalingüística. Molt probablement això va dependre del fet que amb aquest tipus de RCO la docent indicava clarament on era el problema $i$ això ajudava l'alumne a identificar-lo i situar-lo. En aquest sentit, també es necessiten més recerques.

\section{Conclusions}

L Is resultats d'aquest estudi posen en relleu que les - interaccions que es produeixen a l'aula amb alumnes poc escolaritzats inclouen la producció freqüent d'enunciats que contenen més d'un error i de diferents tipus. A més, queda reflectit que en el context català, en les interaccions que es generen a l'aula, hi ha un ús molt elevat del castellà en un moment en el qual s'hauria esperat que els alumnes utilitzessin el català ja que tenen el coneixement per fer-ho. Aquests dos aspectes propicien algunes dinàmiques dins l'aula. D'una banda, en moltes ocasions la docent tria per a la reparació només un dels errors presents a l'enunciat (sobretot els de pronunciació i lèxic) i no es consideren els altres. De l'altra, s'aprecia un ús molt freqüent de la traducció com a tipus de RCO, que no és gaire efectiu en el sentit que no porta els alumnes a incorporar la correcció de la docent a la seva resposta.

Els resultats mostren com la majoria de les RCO són reformulacions que, a diferència del que passa en contextos amb alumnes alfabetitzats, són efectives en el sentit que produeixen una reparació de l'alumne encara que es tracti només d'una repetició de l'enunciat del docent.

Aquest estudi té unes limitacions que s'han de considerar en el moment d'interpretar els resultats, ja que es va dur a terme en un únic centre amb dos grups del mateix nivell, amb un nombre reduït d'alumnes $\mathrm{i}$ en un nombre limitat de sessions enregistrades. Per a futures recerques s'hauria d'ampliar el nombre de participants i grups amb diferents nivells d'alfabetització i esbrinar el nivell de consciència dels alumnes sobre la RCO rebuda, especialment de les reformulacions i dels tipus de RCO més precisos a l'hora d'indicar l'error i que inciten l'alumne a l'autocorrecció.

Finalment, aquest estudi té unes implicacions pedagògiques importants per als docents que treballen en el context penitenciari i, en general, amb alumnes poc escolaritzats. D'una banda, a l'hora de planificar classes de català com a llengua addicional s'ha de tenir en compte l'exposició limitada a la llengua que tenen els alumnes i se'ls ha d'oferir, des del principi, les eines lingüístiques que necessiten per dur a terme les tasques. De l'altra, el docent ha de considerar que l'ús de la reformulació és positiu, però quan ha de reaccionar davant un error hauria d'insistir més amb tipus de RCO com ara l'elicitació i la correcció explícita i la pista metalingüística, que sembla que ajuden l'alumnat a detectar que hi ha un problema i l'acompanyen cap a l'autocorrecció. 


\section{Notes}

1 Per qüestions relacionades amb l'emergència sanitària COVID-19 i les indicacions del Departament d'Educació de la Generalitat de Catalunya i el Departament de Justícia, el centre va decidir dividir cada grup en dos subgrups.

2 Vegeu l'Annex 1 per a les convencions de transcripció de les dades.

\section{Bibliografia}

Alonso Aparicio, I. (2010). Retroalimentación negativa mediante reformulaciones correctivas: impacto en el desarrollo de la distinción modal en español como lengua segunda. Porta Linguarum, 13, 179-195. https://digibug. ugr.es/bitstream/handle/10481/31931/AlonsoAparicio. pdf? sequence $=1$

Bao, R. (2019). Oral corrective feedback in L2 Chinese classes: Teachers beliefs versus their practices. System, $82,140-150$.

https://doi: org/10.1016/j.system.2019.04.004

Bailini, S. (2020). El feedback interactivo y la adquisición del español como lengua extranjera. Mimesis.

Barrionuevo, A., Cutillas, T., i Torner, D. (2009). El Projecte Lingüístic de l'escola de la Model, després de dos anys d'aplicació. Papers d'Educació de Persones Adultes, 61, 19-25.

Bigelow, M., Delmas, R., Hansen, K., i Tarone, E. (2006). Literacy and the processing of oral recasts in SLA. TESOL Quarterly, 40(4), 665-689.

https://doi.org/10.2307/40264303

Birello, M., Pérez Ventayol, M., i Casadellà Matamoros, M. (2017). Los repertorios lingüísticos en las cárceles en Cataluña. Dins A. Benucci i G. Grosso (Eds.), Buone Pratiche e repertori linguistici in carcere (pp. 147-160). Aracne.

Bretxa, V., i Torner, R. (2005). El català ocult: el potencial d'ús de la llengua catalana a la presó model de Barcelona. Llengua i ús: Revista tècnica de política lingüística, 32, 58-69. https://raco.cat/index.php/LlenguaUs/article/ view/128209

Chaudron, C. (1977). A descriptive model of discourse in the corrective treatment of learners' errors. Language Learning, 27, 29-46.

https://doi.org/10.1111/j.1467-1770.1977.tb00290.x
Ellis, R. (2009). Corrective feedback and teacher development. L2 Journal, 1, 3-18.

https://doi.org/10.5070/l2.v1i1.9054

Ellis, R., Basturkmen, H., i Loewen, S. (2001). Learner uptake in communicative ESL lessons. Language Learning, 51, 281-318.

https://doi.org/10.1111/1467-9922.00156

Fernández López, S. (1995). Errores e interlengua el aprendizaje delespañol comolengua extranjera. Didáctica. Lengua y Literatura, 7, 203. https://revistas.ucm.es/ index.php/DIDA/article/view/DIDA9595110203A

Ferreira, A. (2006). Estrategias efectivas de feedback positivo y correctivo en español como lengua extranjera. Revista Signos, 39(62), 379-406.

http://dx.doi.org/10.4067/S0718-09342006000300003

Fu, T., i Nassaji, H. (2016). Corrective feedback, learner uptake, and feedback perception in a Chinese as a foreign language classroom. Studies in Second Language Learning and Teaching, 6(1), 159-181.

https://doi.org/10.14746/ssllt.2016.6.1.8

Hendrickson, J. M. (1978). Error correction in foreign language teaching: Recent theory, research, and practice. Modern Language Journal, 62, 387-398. https://doi.org/10.1111/j.1540-4781.1978.tb02409.x

James, C. (1998). Errors in Language Learning and Use. Exploring Error Analysis. Longman.

Jimenez, J. (2006). Corrective feedback in EFL university classrooms: A case study at an Italian university. Linguistica e Filologia, 23, 45-89. https://aisberg.unibg. it/retrieve/handle/10446/121/1032/Lef23(2006)Jimenez. pdf

Lyster, R., i Mori, H. (2006). Interactional feedback and instructional counterbalance. Studies in Second Language Acquisition, 28(2), 269-300.

https://doi.org/10.1017/S0272263106060128

Lyster, R., i Ranta, L. (1997). Corrective feedback and learner uptake: Negotiation of form in communicative classrooms. Studies in Second Language Acquisition, 19(1), 37-66.

https://doi.org/10.1017/S0272263197001034

Lyster, R. (1998). Negotiation of form, recasts, and explicit correction in relation to error types and learner repair in immersion classrooms. Language Learning, 48(2), 183218.

https://doi.org/10.1111/1467-9922.00039 
Miles, M. B., i Huberman, A. M. (1994). Qualitative data analysis: An expanded sourcebook (2nd ed.). SAGE Publications. https://bit.ly/3vxUto7

Muñoz Moreno, E., i Mavrou, I. (2020). La influencia del componente no verbal asociado al feedback correctivo en la producción oral en ELE. Revista Signos, 53(103), 468-495.

http://dx.doi.org/10.4067/S0718-09342020000200468

Nassaji, H. (2009) Effects of recasts and elicitations in dyadic interaction and the role of feedback explicitness. Language Learning, 59(2), 411-452.

http://dx.doi.org/10.4067/S0718-09342020000200468

Panova, I., i Lyster, R. (2002). Patterns of corrective feedback and uptake in an adult ESL classroom. TESOL Quarterly, 36(4), 573-595.

https://doi.org/10.2307/3588241

Philp, J. (2003). Constraints on 'noticing the gap': Nonnative speakers' noticing in recasts in NS-NNS interaction. Studies in Second Language Acquisition, 25, 99-126.

https://doi.org/10.1017/S0272263103000044

Ranta, L., i Lyster, R. (2007). A cognitive approach to improving immersion students' oral language abilities: The Awareness-Practice-Feedback sequence. Dins R. DeKeyser. (Ed.), Practice in a second language: Perspectives from applied linguistics and cognitive psychology (pp. 141-160). Cambridge University Press.

https://doi.org/10.1017/СВ09780511667275.009

Sánchez Calderón, S. (2014). Los efectos de las estrategias de retroalimentación oral en la adquisición de segundas lenguas. Colindancias, 5, 283-311. https://colindancias. uvt.ro/index.php/colindancias/article/view/55/0

Sans Bertran, M. T. (2018). Repertori i usos lingüístics d'un alumne intern d'origen marroquí d'un centre penitenciari de l'àrea metropolitana de Barcelona. Bellaterra Journal of Teaching \& Learning Language \& Literature, 11(3), 64-86.

\section{http://doi.org/10.5565/rev/jtl3.744}

Shirani, R. (2019). Patterns of uptake and repair following recasts and prompts in an EFL context: Does feedback explicitness play a role?, Studies in Second Language Learning and Teaching, 9(4), 607-631.

http://dx.doi.org/10.14746/ssllt.2019.9.4.3

Strube, S. (2006). Recasts and learner uptake: the non-literate adult L2 classroom during oral skills practices. Dins M. Young-Scholten (Ed.). Proceedings of the Third Annual LESLLA Forum (pp.61-75). Roundtuit Publishing. https://drive.google.com/file/d/1Plbg1SqoxZ6AQNlum B4OO7ukPwFjxYtk/view
Tarone, E., i Bigelow, M. (2007). Impact of literacy on oral language processing: Implication for second language acquisition research. Dins A. Mackey (Ed.) Conversational interaction in second language acquisition: A series of empirical studies (pp.101-121). Oxford University Press.

Tarone, E., Bigelow, M., i Hansen, K. (2009). Literacy and second language oracy. Oxford University Press.

Tarone, E. (2010). Second Language acquisition by lowliterate learners: An under-studied population. Language Teaching, 43(1), 75-83.

https://doi.org/10.1017/S0261444809005734

Tarone, E. (2021). Alphabetic print literacy level and noticing oral corrective feedback in SLA. Dins H. Nassaji i E. Kartchava (Eds.), The Cambridge handbook of corrective feedback in second language learning and teaching (pp. 450-470). Cambridge University Press.

https://doi.org/10.1017/9781108589789.022

Van Lier, L. (1988). The classroom and the language learner. Longman.

Vázquez, G. (1999). ¿Errores? ¡Sin falta!. Edelsa.

Vázquez, G. (1992). Análisis de errores y aprendizaje de español/lengua extranjera. Peter Lang.

Veliz Campos, L. (2008). Corrective feedback in second Language classrooms. Literatura y Lingüística, 19, 283292.

https://doi.org/10.4067/S0716-58112008000100016

Vila, X. F., Sorolla, N., i Larrea, I. (2013). Les vies per als aprenentatges lingüístics del jovent d'origen marroquí establert a Catalunya. Dins F . X. Vila i E. Salvat (Eds.). Noves immigracions i llengües (pp. 147-197). Agrupació d'Editors i Autors Universitaris. 


\section{Annex 1}

Convencions de transcripció

\begin{tabular}{|c|c|}
\hline $\mathrm{E}, \mathrm{E} 1, \mathrm{E} 2:$ & estudiant \\
\hline P : & professor \\
\hline va! & èmfasi $a m b$ to descendent \\
\hline què és? & to ascendent, pregunta \\
\hline no: : : & allargament de so \\
\hline $\mathrm{CO}-$ & interrupció abrupta \\
\hline$=$ & torn que continua més a baix \\
\hline$(($ riure $))$ & comentaris \\
\hline negreta & ús altres llengües \\
\hline$[$ ta' Ker] & transcripció fonètica \\
\hline$()$. & pausa breu \\
\hline lectura & lectura en veu alta de l'enunciat de l'activitat \\
\hline KXX & incomprensible \\
\hline
\end{tabular}

